\title{
MÚSICA ELETRÓNICA DE DANÇA: AMBIGUIDADES DISCURSIVAS
}

\author{
Alexandre Ferreira \& Jean-Martin Rabot
}

\begin{abstract}
RESUMO
Este artigo reflete sobre as ambiguidades que constituem os discursos em torno da música eletrónica de dança, pondo em evidência o carácter socialmente construído dos mesmos. Sob o ponto de vista dos Estudos Culturais, incidiremos particularmente no house e no techno. A sua estreita ligação com a tecnologia constituiu uma mudança paradigmática na forma como se faz e entende música no século XXI. Pretendemos posicionar o nosso olhar para a importância que este género pode representar na formação dos estudantes de música em Portugal, designadamente no ensino superior.
\end{abstract}

\section{PaLAVRas-chave}

Música eletrónica de dança; novas tecnologias; ensino de música; Estudos Culturais

\begin{abstract}
This article reflects on the ambiguities that constitute the discourses around the electronic dance music, highlighting the socially constructed character of the same ones. From the point of view of Cultural Studies, we will focus on house and techno. Its close connection with technology has constituted a paradigm shift in the way music is done and understood in the $21^{\text {st }}$ century. We intend to position our view to the importance that this genre can represent in the training of music students in Portugal, namely in higher education.
\end{abstract}

\section{PaLAVRAS-Chave}

Electronic dance music; new technologies; music teaching; Cultural Studies

\section{INTRODUÇÃo}

Num artigo pulicado por Varèse e Wen-chung (1966), já se falava em formas eletrónicas de produzir novos sons, nunca antes ouvidos. Eles iriam desafiar a música que era feita até então, conseguindo, por exemplo, alcançar frequências que não eram possíveis. A própria notação musical adivinhava-se imprópria para este novo mundo da tecnologia musical. Varèse e Wen-chung enfrentou, obviamente, duras críticas sobre querer acabar com os instrumentos tradicionais e com as grandes obras do passado, no entanto, ele queria apenas "produzir uma nova flor". Não interessava se à primeira vista se parecia mais com um cato do que com uma rosa" (Varèse \& Wen-chung, 1966, p. 15). Como Varèse e Wen-chung diziam, a eletrónica era um aditivo para a música e não um factor destrutivo da arte. Para os autores, a electrónica permitiu aos compositores a libertação do sistema tonal, cheio de regras, e a exploração de novos tímbres, com uma panóplia 
interminável de novos sons. Porém, Varèse e Wen-chung acreditavam que não demoraria muito tempo até que alguém se lembrasse de regrar todo este novo mundo.

Em todo o caso, parece-nos que a música electrónica foi bem recebida pelos ouvintes, tendo em conta a imensidão de músicos e compositores que proliferam no mundo da música neste género, pelo menos na esfera "popular". Além disso, a facilidade de qualquer pessoa compor uma obra musical, com recurso aos novos softwares de criação musical (que não têm como requisito de utilização conhecimentos de composição aprofundados), torna a figura do compositor mais "popular" e menos elitizada. Contudo, ainda não sabemos se estes compositores mais "populares" são reconhecidos no ensino superior de música.

Foi com o surgimento da fita magnética, que trouxe a possibilidade de gravar sons de qualquer fonte sonora, que o mundo musical se começou a revolucionar (Chadabe \& Torres Lima, 2014).

Várias correntes musicais foram surgindo, como a música concreta, em Paris, de Pierre Shaeffer e Pierre Henry, que consistia em gravar sons existentes do meio natural para posteriormente serem transformados eletronicamente (Chadabe \& Torres Lima, 2014). Já nos Estados Unidos da América, John Cage, nas suas obras, utilizava sons não-tradicionais, como rádios e latas, e em Colónia, Karlheinz Stockhausen, que havia estudado em Paris com Shaeffer, introduziu a composição com sons puramente eletrónicos. Este encontro da tecnologia com a música foi só o início do que estaria para vir em relação à música eletrónica.

Foi um momento marcante na história da música em que, para muitos compositores, parecia que tudo era possível. Em todo o mundo eles compartilhavam o objetivo comum de criar um novo tipo de música baseada na disponibilidade de todos os sons. (Chadabe \& Torres Lima, 2014, p. 19)

Foi em 1957 que se pôde ouvir, nos laboratórios Bell Thelephone, o primeiro som gerado por um programa para o efeito - Music I - com auxílio de um computador (Chadabe \& Torres Lima, 2014). O próprio conceito de música estava em mutação, pelo menos na cultura ocidental.

John Cage foi também o autor de uma obra que causou imensa controvérsia - 4'33. Tratam-se de quatro minutos e trinta e três segundos de silêncio, com o intuito de romper com o conceito de música vigente, e argumentar que o silêncio é parte integrante e essencial da música. Para Cage, a música era o som, fossem ruídos ou sons "dignos" de pertencerem à partitura. Na sua obra Silence: Lectures and Writtings (1961), (re)conceptualiza o que é considerado música explorando os desenvolvimentos tecnológicos, como a possibilidade de gravação áudio, bem como a condição obsoleta da partitura face à notação dos novos sons. Na verdade, não era difícil perceber que a panóplia de sons existentes na natureza iam além da notação musical convencionada, mas a força dos cânones e de uma tradição de séculos sonegou insistentemente essa realidade.

"Nova música: nova escuta" (Cage, 1961, p. 10). Cage tinha obviamente uma conceção da música muito à frente do seu tempo, e é curioso o facto de ser um músico tido como "erudito", uma vez que é estudado nos livros de história da música ocidental, no 
entanto, não se pode negar que o seu pensamento chocou com os valores musicais sacralizados.

Direcionaremos a nossa atenção, neste artigo, para a música eletrónica de dança (MED), no entanto, não será possível abordar todos os estilos que lhe pertencem. A própria denominação é bastante genérica (Fraser, 2012). Incidiremos, particularmente, sobre o house e o techno, apesar de reconhecermos que esta esfera da música comporta uma profusão de géneros como nenhuma outra. À primeira vista, para um outsider, pode aparentar que os nomes associados a cada estilo são idênticos (acid house, acid techno, hardcore techno, aquatic-house) mas para um insider, representam diferenças significativas (McLeod, 2001). A influência deste tipo de música tem crescido exponencialmente e desenvolveu uma estreita relação com a tecnologia:

essas variedades musicais são feitas maioritariamente pela combinação de hardware como samplers, sintetizadores, caixas de ritmos, com software de produção musical sofisticado operado por computadores. Tais tecnologias tornam possível para um artista ou produtor fazer Música Eletrónica de Dança sem saber como tocar um instrumento musical - uma ideia estranha na geo-história da música. (Fraser, 2012, p. 500)

Para além desta sinergia, existe uma associação ao mundo das drogas, especialmente ao MDMA (também conhecido como ecstasy), que impulsionou, em certa medida, a criação de beats cada vez mais eufóricos (Fraser, 2012). Fraser argumenta que, a MED é, pela sua relação com o consumo de certas substâncias, associada ao hedonismo e a locais de consumo específicos, como os clubes noturnos. Reconhecendo que tem um carácter subversivo e político, não é lógico que essas características soneguem o seu valor musical. Aliás, o reconhecimento académico da cultura da música eletrónica de dança tem aumentado. A urgência na investigação prende-se, segundo Graham (2009, p. iii), com as fugazes mutações que a caracterizam: "mesmo o género, subgénero ou microgénero que pensávamos conhecer ontem está a passar por um trânsito que já mal conseguimos identificar".

A música eletrónica de dança, particularmente os géneros house e techno, tem grande expressão na contemporaneidade e é um estilo de dança dominante em Portugal (Silva, 2005). É um dos expoentes máximos da fusão entre a tecnologia e a criação musical que, no entanto, dependendo do contexto que a recebe, gera animosidades e entusiasmos, que tanto pode representar a elite ou a massa, ser "erudita" ou "popular", mainstream ou subalterna. Estas ambiguidades poderão ser o resultado das relações culturais que permeiam a esfera da música, pondo em confronto uma série de questões como a autenticidade, o valor cultural, a definição de música e músico, e a constante luta entre o bloco de poder e o "povo".

Pretendemos refletir sobre a MED através da perspetiva teórica dos Estudos Culturais, nomeadamente a noção de popular que Hall (2003) prefere adotar. O "popular" é definido consoante as relações de poder entre a cultura dominante e a dominada. Depende sempre do seu contexto histórico e social. Torna-se, assim, difícil dizer que determinada obra musical é popular, e a outra não, pois está dependente dos jogos de 
poder entre culturas, e estes jogos vão mudando as suas regras. Este pensamento é bem retratado na obra de Hall (2003), que considera que os objetos culturais não têm um valor intrínseco, este é determinado pelo contexto cultural. Qual é então a relevância académica na desconstrução dos discursos em torno da MED? Uma vez que, hoje em dia, quase toda a música é eletrónica (Reynolds, 2007), no sentido em que está de alguma maneira dependente das tecnologias de criação e produção sonora, torna-se relevante perspetivar a MED pelos significados culturais que alicerça, pelas identidades que transporta e pela música que produz. Apesar de algumas destas questões já serem amplamente abordadas em várias disciplinas académicas, no ensino da música, sobretudo no ensino superior, poderá haver resistência em legitimar este género. Os currículos nos conservatórios têm veiculado a ideia de uma música autêntica, baseada nos valores da música erudita ocidental, conforme as reflexões de alguns estudos a este respeito (Arroyo, 2001; McCarthy-Brown, 2014; Mota, 2015; Nompula, 2011; VanWeelden, 2012). Torna-se legítimo pensar que o mesmo se transporta para o ensino universitário. A persistência de tais ideais poderá contribuir para a formação de músicos que não considerem a MED como uma forma musical válida, perpetuando, assim, a luta entre cultura "popular" e "erudita".

O objetivo deste texto é contribuir para a desconstrução dos discursos que envolvem a MED, esperando também colaborar para a democratização do currículo no ensino superior de música, face aos seus conteúdos e objetivos, pensado no diálogo entre estudantes, instituições de ensino e sociedade.

\section{ENTRE O “POPUlAR" E O “ERUDITO”}

A primeira ambiguidade que pretendemos abordar está relacionada com a incerteza da inclusão da MED no domínio do "popular" ou do "erudito". Por mais que nos posicionemos com a perspetiva de Hall (2003), concordando que estas classificações são voláteis e se transfiguram, não podemos negar a sua existência na sociedade. $O$ autor afirma que estas classificações pouco têm que ver com o produto cultural em si.

$\mathrm{Na}$ sua visão, o termo popular pode ser entendido de maneiras distintas, sendo uma delas a sua ligação com o tradicional, o retrógrado e o conservador. Essas conotações derivam do período em que o capitalismo industrial necessitava de se aproximar das classes trabalhadoras e do povo, com vista a uma nova ordem social em torno do capital, e estas classes eram sempre as que apresentavam maior resistência (Hall, 2003). Ainda nos diz que, no senso comum algo é popular se é consumido pelas massas e estas, por sua vez, escutam, leem, compram e consomem os produtos insistentemente, servindo esta definição para efeitos mercadológicos. Portanto, o popular, neste sentido, está associado à manipulação das massas, facto que Stuart Hall não nega, mas também não concorda totalmente. Categoricamente, afirma que "não existe uma 'cultura popular' íntegra, autêntica e autónoma, situada fora do campo de força das relações de poder e de dominação culturais" (Hall, 2003, p. 254). Segundo o autor, o povo não é um "tolo cultural" (Hall, 2003, p. 253) e apercebe-se da manipulação feita pelas indústrias 
culturais capitalistas e por isso, por vezes, apresentam resistência, transformando o aspeto cultural num campo de batalha social. Ora, se os produtos culturais não são na sua totalidade manipuladores é porque existe uma identificação com os mesmos (Hall, 2003). A indústria cultural da música não funcionará de maneira distinta, certamente. Do nosso ponto de vista, uma das batalhas culturais que a MED terá de travar prende-se com a sua inclusão nas instituições de ensino superior de música, nomeadamente aquelas que centram a sua atividade na formação de performers com os instrumentos musicais considerados mais tradicionais (violino, piano, canto, etc.).

A afirmação da música eletrónica, em geral, tem gerado controvérsia e resistência entre os cientistas musicais, compositores e músicos em geral. Para citar um exemplo, no livro História da Música Ocidental de Grout e Palisca (1998, p. 746) pode ler-se que "a música eletrónica e sintetizada não destronou, nem é possível que venha a destronar, a música executada ao vivo". A música eletrónica a que os autores se referem não é a MED, essa, apesar de ter surgido já nos anos 1970 (Reynolds, 2007), não é citada na obra. Falamos, portanto, de outras correntes da música eletrónica, como a música concreta ou a música eletrónica com recurso à banda magnética. No entanto, estes últimos géneros eletrónicos são geralmente discutidos e abordados nos currículos dos músicos de formação "erudita" por estarem associados à academia e à sua pertença a uma tradição artística, ao passo que, a MED se refere à produção musical de origem "popular" (Martin, 2012). Será legítimo inferir que, existe uma "alta" música eletrónica e outra que pertence às camadas "populares", concordando que a segunda não despoleta grande interesse académico. O que pretendemos afirmar é que, na verdade, não existem razões coerentes para esta diferenciação, a não ser o facto de a MED apelar à dança, ao prazer e à fruição musical. Pedro Ferreira (2008) reitera que a música eletrónica de dança não pode ser pensada sem essa dimensão - a dança. De acordo com o seu ponto de vista, não podemos pensar e assumir que este género dá continuidade à música concreta ou música eletroacústica, considera, aliás, essa lógica um erro crasso. Revela ainda que, alguns compositores "eruditos", como Stockhausen, revelam incompreensão e até uma certa repulsa face à MED.

A MED é um género musical com conceitos e estéticas próprias e teve a sua origem nos Estados Unidos - o house em Chicago e o techno em Detroit. Surge inicialmente associada às minorias sociais como os negros, os homossexuais, entre outros comportamentos sociais que poderão fugir às normas convencionadas (Reynolds, 2007). Mas, se no início poderia ser considerado um género underground, é certo que na sociedade contemporânea está bem presente e difundida, contando com festivais de música dedicados ao género, como o Tomorrowland ou o Ultra Music Festival. Por vezes definida como música-máquina, tende a perspetivar e produzir música de forma distinta das formas clássicas, onde o processo de criação é mais relevante que a própria performance. Mais, Reynolds (citado por Boia, Ferro \& Guerra, 2010), afirma que o género eletrónico desafia o corpo humano pela sua variabilidade rítmica e pelas texturas que a música encerra. Já para Wiltsher (2016), a estética da música eletrónica de dança valoriza aspetos como a funcionalidade, os sons eletrónicos e a repetição. O autor reitera que o apelo à dança é nuclear, e quanto mais servir essa função, mais bela ela se torna. Os sons 
produzidos por sintetizadores, samplers, entre outros, representam outras das valorizações estéticas. Por fim, a repetição, como Wiltsher sugere, com a sobreposição de loops', melodias ou harmonias, que se vão alternando ao longo da faixa, dão uma sensação de progresso. Os compositores deste género estão cientes desta forma nas faixas, o que as aproxima, em termos de composição, à música "erudita" (Wilsher, 2016). Segundo o autor, os compositores trabalham com regras rígidas para poderem trocar as suas obras e permitir a remixagem mais facilmente.

A semelhança entre o formalismo valorizado na música "erudita" e na MED são óbvias e evidentes, mas a simplicidade harmónica e melódica do segundo género pode pesar para a sua "popularidade". Isto, porque os músicos de formação clássica são treinados para ouvir progressões harmónicas ou melodias, representando isso o foco principal da música, no entanto, na MED, as harmonias e melodias são muitas vezes rudimentares (Reynolds, 2007). Se fossem muito complexas iriam distrair o ouvinte para o seu foco principal: o som e os contrastes tímbricos. Reynolds adverte ainda sobre a fisicalidade da eletrónica, no sentido em que, todo o corpo se envolve nas vibrações pujantes dos sistemas de som dos clubes, tornando-a sobretudo numa experiência física, com óbvios reflexos na mente. Apesar disto, a "alta" música eletrónica também não usa os métodos de composição tradicionais, mas o seu espírito vanguardista pode valer-lhe a etiqueta de "erudito". Se pretendermos falar de vanguarda na MED, ela encontra-se nos próprios sons, onde os criadores estão constantemente a procurar novas formas de sintetizar, transformar e misturar: "gostam de descrever o que fazem como investigação científica, imaginando o estúdio como um laboratório de som" (Reynolds, 2007, p. 313). Podemos dizer que a MED tanto pode ser "erudita" como "popular" visto que, em diferentes contextos, ela opera de diferentes formas. É "erudita" quando é percecionada através do seu processo criativo e composicional, que tem semelhanças com as obras musicais "eruditas". Poderá não ser tão complexa a nível harmónico e melódico mas é nos seus sons, ritmos, e no efeito que produz junto da plateia dançante que ela adquire o seu grau de complexidade.

A MED é também "popular" quando vista sob o plano de consumo musical das massas onde se verifica que "a música house domina quase por completo as discotecas e clubes do país (Portugal)" (Silva, 2005, p. 67). Inferimos, portanto, que a ambiguidade aqui apresentada poderá estar conectada com a esfera do poder, seja institucional, cultural ou mesmo político. A MED poderá estar a ser negligenciada ao nível da formação académica apenas por ter uma conotação "popular", que nada tem que ver com a música em si, mas apenas com o contexto em que se produz.

Tomando como exemplo o estudo de MacCutcheon, Greasley e Elliott (2016) podemos observar que os participantes consideraram, unanimemente, que a prática do $D J^{2}$ desenvolve competências musicais, sobretudo a nível rítmico. Não menos importante foi a referência a conhecimentos estruturais da música, como o reconhecimento de frases musicais e compassos, bem como conhecimentos tecnológicos e performativos inerentes à prática do DJ.

\footnotetext{
' Loop: trata-se de um sample (amostra sonora) que está em constante repetição.

${ }^{2}$ DJ (Disc jockey) artista que reproduz as faixas criadas eletronicamente e as remixa em tempo real.
} 
À questão se o DJ tinha tanta relevância cultural como o músico de tradição clássica, surpreendentemente, os músicos de formação clássica responderam que tinha a mesma ou relevância superior. Já alguns elementos do grupo dos não-músicos e DJ's responderam que tinha menos relevância cultural. Os autores esperavam que cada grupo defendesse os seus interesses, mas tal não aconteceu.

Poderão estar as universidades resistentes a uma mudança de paradigma da música e dos músicos no século XXI?

\section{Os CONTRIBUTOS DA MED PARA A (RE)DEFINIÇÃO DE INSTRUMENTO MUSICAL E MÚSICO}

No século XX, Varèse e Wen-chung (1966) antevia uma nova estética e estava certíssimo quando se deu conta que, a música dos novos instrumentos eletrónicos iria trazer possibilidades de conjugar ritmos, melodias e harmonias que iam além das capacidades do ser humano.

Os primeiros instrumentos musicais eletrónicos como o Telarmónio, o Theremin, o Trautónio, o Ondes Martenot, o órgão eletrónico, a cítara eletrónica e o sintetizador RCA, trouxeram com eles novos sons destinados a interpretar a música na mesma linha do que os instrumentos tradicionais já faziam (Chadabe \& Torres Lima, 2014).

Quando pensamos sobre o conceito de instrumento musical associamos tradicionalmente a um objeto construído de madeira ou metal que possua capacidades de ressonância (Tanaka, 2006). De acordo com Tanaka, são objetos manipulados pelos seres humanos que exploram as capacidades vibratórias dos mesmos, de forma a produzir melodias e harmonias através das suas qualidades tímbricas específicas. No caso dos instrumentos musicais que abraçaram as tecnologias, a premissa de manipulação física pelos humanos foi mantida. No universo da música pop, os instrumentos mais utilizados para a criação musical são os computadores, tablets ou smartphones, substitutos da usual guitarra clássica (Neill, 2002). Serão estes dispositivos os novos instrumentos do século XXI?

Eu afirmo que as tecnologias digitais possuem uma voz da mesma forma que um instrumento musical tradicional possui. Considerando que no caso dos instrumentos digitais, que são processados por computadores de uso geral, cada sistema interativo traz consigo uma personalidade própria. (Tanaka, 2006, p. 270)

A organologia, conforme consta no dicionário de música (Borba \& Lopes-Graça, 1958, p. 320) é a "ciência que trata dos instrumentos em geral, sua classificação, especificação de timbres, recursos, etc.". Ter conhecimentos aprofundados nesta área é importante para qualquer músico, mas essencial para os compositores porque estes, a princípio, irão compor melhor para determinado instrumento se conhecerem as suas possibilidades e limitações.

Tanaka (2006) expõe-nos à família dos sensor instruments. Instrumentos que, tal como na família das cordas ou sopros (exposto de forma simplista e tendo consciência 
de que estas famílias podem ser subdivididas, por exemplo cordas friccionadas ou dedilhadas, e até renomeadas por outros autores como von Hornbostel \& Sachs,1961), possuem um elemento em comum, neste caso movimentos gestuais com as mãos, articulados com um recetor de movimentos e sintetizadores digitais (no computador). A autora argumenta que, no entanto, cada um dos instrumentos tem a sua própria identidade musical, na medida em que possuem características distintivas entre si, tal como o violino e o violoncelo na família das cordas. Portanto, estes instrumentos poderão ser melhor compreendidos se se tiver em conta as suas particularidades (escrita idiomáti$\mathrm{ca}^{3}$ ), e desta forma familiarizar os ouvintes com estes sons, para que estas formas e instrumentos musicais sejam compreendidos (Tanaka, 2006). O facto mais interessante, aqui, é precisamente este exemplo constituir mais uma prova de que a música e a forma como fazemos música está em constante mutação e redefinição. Defendemos que a formação académica deve abrir os horizontes para estas matérias de modo a que a inovação e a criatividade não se esgotem, e claro, com isto, estimular um discurso académico sobre música mais recetivo às inovações que proliferam diariamente. No entanto, não podemos sonegar que as universidades estão abertas aos avanços tecnológicos, até porque, a título de exemplo, a ESMAE (Escola Superior de Música e Artes do Espetáculo) e a ESML (Escola Superior de Música de Lisboa) possuem licenciaturas voltadas para a produção e tecnologias da música4.

É um facto que na música eletrónica o computador é o instrumento musical de eleição (Reynolds, 2007). As suas possibilidades na área do som e da música permitiram trazer novas realidades aos performers. Quem o diz é Garnett (2001), num artigo sobre a estética da música interativa, que nos fala sobre a capacidade de o computador se tornar numa extensão do performer, na medida em que consegue processar o som e dar-lhe novas texturas em tempo real, entre outras coisas. É precisamente neste ponto de vista em que o autor se quer focar, a integração da máquina na vida do ser humano como impulsionador não só da técnica mas também da expressão humana. Para Garnett, a dicotomia máquina/homem ou música-máquina/música-humana já não são tão relevantes e, na sua visão, devemos caminhar, como já acontece com as gerações mais jovens, para a aceitação da tecnologia como parte integrante da nossa vida em todos os aspetos.

No caso da música eletrónica de dança, um dos instrumentos frequentemente utilizado é o sampler - software ou hardware que armazena amostras sonoras (samples). De acordo com Rodgers (2003), o sampling (manipulação e mistura dos samples para criar novos padrões rítmicos e melódicos) é o processo criativo onde os compositores de MED despendem mais tempo (cerca de 50\%) até terem a música terminada. Esse dispositivo tecnológico (sampler), como refere a autora, veio desestabilizar as fronteiras

\footnotetext{
3 "Na música, o que identifica o idiomatismo em uma obra é a utilização das condições particulares do meio de expressão para o qual ela é escrita (instrumento/s, voz/es, multimídia ou conjuntos mistos). As condições oferecidas por um veículo incluem aspetos como: timbre, registro, articulação, afinação e expressões. Quanto mais uma obra explora aspetos que são peculiares de um determinado meio de expressão, utilizando recursos que o identificam e o diferenciam de outros meios, mais idiomática ela se torna" (Tullio, 2005, p. 299).
}

${ }^{4} \mathrm{~A}$ nossa pesquisa futura, no âmbito de um programa doutoral em Estudos Culturais, revelará em que medida a MED se inclui nestes cursos. 
do que é considerado um instrumento musical. Argumenta que os instrumentos tradicionais (violino, trompete, etc.) estão condicionados a nível sonoro pelas suas propriedades físicas. Um violino soará sempre a um violino, ao passo que, o sampler pode reproduzir uma infinidade de sons e está dependente de fatores como a capacidade da memória, a dependência da corrente elétrica, entre outros. Rodgers refere que, tal como há violinistas que preferem tocar um Guanierius em vez de um Stradivarius, aqui os compositores também optam por diferentes samplers, de acordo com o que consideram ser o melhor para as suas criações.

Portanto, outra das ambiguidades que circunda a MED tem que ver com os próprios instrumentos musicais utilizados. Torna-se árduo perspetivar os mesmos com os conceitos e definições que podem já estar desatualizados. Questões como a própria conceptualização de instrumento musical, que como vimos no caso da MED pode ter contornos bem distintos, são essenciais no discurso académico sobre música, caso contrário, instrumentos como o sampler ou até instrumentos musicais que só existem no mundo virtual serão considerados apenas como ferramentas (Tanaka, 2006). Ferramentas, porque é pensado como algo que melhora as nossas capacidades e possibilidades em determinadas atividades, ao passo que o instrumento musical vai sendo melhorado, não por razões práticas, mas por razões expressivas (produzir som com mais qualidade, por exemplo). Para Tanaka, a questão centra-se em entender se os softwares foram criados para a otimização de um mundo musical existente ou se essa digitalização musical contém, por si só, potencial artístico. De uma coisa tem a certeza, as possibilidades tecnológicas têm vindo a democratizar o processo criativo, o que implicará uma redefinição da figura do próprio músico. Outro aspeto que nos parece relevante é o de que a não-aceitação de novos instrumentos musicais impedirá, pelo menos em contexto académico e de formação dos alunos de música, o cruzamento entre os instrumentos tradicionais e os "não-tradicionais". Poderia resultar em novo conhecimento, em novas correntes artísticas ou em novas possibilidades performativas.

Também na figura do músico a MED tem contribuído para uma nova definição. De acordo com Boia, Ferro e Guerra (2010), a figura do DJ assume um papel relevante na proliferação de novas sonoridades. A produção musical está entregue a uma "equipa" que trabalha em conjunto por diversas circunstâncias (ligação da indústria musical com os criadores/produtores musicais, por exemplo), sendo uma junção essencial que, no nosso entender, caracteriza o processo de criação e composição de música eletrónica. Contudo, os métodos tradicionais de aprendizagem musical não estão necessariamente em sintonia com os novos contextos educativos, sobretudo no que respeita à inclusão das novas práticas e instrumentos musicais advindos dos avanços tecnológicos (MacCutcheon et al., 2016). A investigação das práticas dos DJ's na academia permanece pouco explorada, indicando que há muito para fazer neste campo (MacCutcheon et al., 2016).

O estudo realizado por MacCutcheon e colegas (2016) mostra-nos que os intervenientes inquiridos (sete instrumentistas de cordas, sete não músicos e sete D)'s profissionais) admitem que os DJ's podem ser considerados músicos. Um interveniente revelou, inclusivamente, que o domínio do DJ sobre a tecnologia pode ser equiparado 
ao domínio de um pianista sobre o piano. Outro dos intervenientes comparou a prática de um compositor, que utiliza os timbres dos instrumentos tradicionais para compor as suas obras, à prática do DJ na recolha de samples para criar algo novo.

À questão se as aulas de DJ deveriam ser incluídas no currículo formal, $62 \%$ responderam que sim, $14 \%$ responderam que deveria ser opcional, $14 \%$ responderam que não sabiam e 10\% responderam que não deveria ser parte integrante do currículo.

A opinião dos professores sobre os workshops de DJ que foram ministrados por dois DJ profissionais em escolas de ensino secundário demonstrou que, inicialmente todos estavam muito focados nas desvantagens destas práticas e matérias, mas, no final, percebeu-se que mudaram radicalmente a sua posição. Encontraram bastantes pontos positivos como a criatividade e o desenvolvimento de competências musicais.

A prática do DJ é muitas vezes vista como uma arte menor, apesar de o estudo de Huq (2007) apontar noutra direção. A autora expõe o caso de uma violoncelista de formação clássica que foi desafiada a fazer uma performance como DJ, com uma preparação de quatro semanas. Concluiu que, "a implicação por trás da aquisição das competências necessárias para mixar gravações no tempo e simultaneamente satisfazer a multidão presente não era 'tão fácil como parecia'" (Huq, 2007, p. 97).

Para Martin (2012), mesmo a prática docente de música eletrónica "erudita", pelo menos na realidade do autor (um conservatório na China), tem incidido sobre características como duração ou afinação, que fazem sentido em certas obras, mas revela que esta abordagem negligencia um entendimento que vá além das fronteiras impostas pela tradição musical ocidental. O autor defende que, só será possível inverter esta situação quando os professores dominarem em profundidade as técnicas e os processos de composição da música eletrónica.

Sem um entendimento prático e conceptual suficiente sobre os procedimentos, estruturas, significados e propósitos únicos às práticas da música eletrónica, o ensino estaria dependente das premissas derivadas da experiência com os modelos de afinação-duração (adquiridos através da performance e audição). (Martin, 2012, p. 128)

Para Martin, uma das razões para a falta de formação dos professores nesta área tem que ver, precisamente, com a escassa abordagem à música eletrónica na formação universitária. De ressalvar que, o autor encara o conceito de tradição, não como uma entidade histórica fixa, mas antes aberta à confluência e à transformação.

Se há muito para ser discutido em relação às práticas docentes da música eletrónica que já se encontra nos currículos, há ainda muito mais para ser investigado no panorama da Música Eletrónica de Dança. Pensamos que essa responsabilidade passa, impreterivelmente, pelas instituições de ensino que são responsáveis pela formação dos nossos músicos em Portugal. Farrugia (2012), por exemplo, tem investigado sobre a relação de género com tecnologia, na cultura musical popular, concluindo que a representatividade masculina no setor é assumidamente maior que a feminina. Refere-se, por exemplo, ao facto de a maioria dos DJ's serem homens, assim como estrelas do 
rock, produtores, entre outros. Estas evidências estão relacionadas com os discursos socialmente construídos em torno do género e tecnologia, uma vez que a competência tecnológica sempre esteve associada à masculinidade (Farrugia, 2012). Pese embora, no campo da música pop, grande parte dos artistas são mulheres, isto porque, como Farrugia (2012) refere citanto Lucy Green, o canto é considerado uma atividade mais feminina e, por isso, as mulheres costumam estar conectadas ao mundo da música ou pela dança, ou pela voz. A relação das mulheres com tecnologia é vista pela sociedade como passiva, ou seja, são apenas utilizadoras da mesma (Farrugia, 2012). A inclusão da MED no ensino superior poderá alicerçar mudanças nos discursos sociais sobre vários assuntos como: música, género, poder, cultura, entre outros.

Numa forma conclusiva, podemos dizer que as tecnologias e os meios eletrónicos estão a tornar-se as novas vozes da cultura popular. A expansão da música eletrónica e da estética que lhe é associada tem como tradução profundas mudanças na forma como ouvimos e apreciamos a música (Boia, et al., 2010, p. 54).

Consideramos que os músicos, estudantes de música, investigadores em música e restantes intervenientes na formação académica, particularmente no ensino superior, devem estar abertos para estas mudanças na história da música, repensar o valor musical das práticas "populares" e o seu contributo para a literacia musical.

\section{ENTRE O MAINSTREAM E A SUBALTERNIDADE}

A última ambiguidade que iremos apresentar prende-se com a polaridade entre o mainstream e a subalternidade. Pretendemos afirmar que a MED, neste artigo com especial ênfase para os subgéneros house e techno, poderá ser adjetivada e associada aos dois. O quadro da subalternidade remete-nos, em primeiro lugar, para a sua génese nos Estados Unidos da América.

O house surge em Chicago, na década de 1970, caracterizando-se inicialmente como um género underground; o seu nome deriva de um dos clubes onde se ouvia esta música - wharehouse (Reynolds, 1998). O clube era inicialmente frequentado por gays, negros e latinos, e o house misturava o soul, R\&B, funk, salsa e rock, com mensagens de amor e sexualidade, impulsionado por ritmos frenéticos e repetitivos (Boia et al., 2010). Reynolds (1998) argumenta que, o house veio ressuscitar a música de dança, mudando a sua forma, causando mau estar através da intensificação de características como a repetição extrema, sons cada vez mais artificiais, e a sua estreita ligação com o hedonismo e as drogas. O house afirmava-se não como um género distinto mas como uma aproximação à cultura de dança, que estava em decadência, morta, e ressuscitou-a através de colagens, remixagens, enfim, uma nova abordagem (Reynolds, 1998). No house, o compositor tem o nome de produtor e o protagonismo recai muito sobre ele, embora se rejeite o culto da imagem (ao contrário do pop). É um género que transporta consigo valores de união, resiliência, orgulho, como de alienação social, comportamentos 
desviantes e consumo de drogas. Deve-se, sobretudo, à participação da comunidade gay, que abraçou o género, e de certa forma, transformou-se na banda sonora das suas causas políticas e de afirmação na sociedade (Reynolds, 1998). Segundo Reynolds, o House oferecia uma sensação de comunhão e comunidade para todos aqueles que eram alienados pelos seus comportamentos sexuais transgressores. Funcionava quase como uma religião, e o warehouse, em Chicago, era a sua igreja. As pequenas frases proferidas nas faixas house, pelo menos na sua fase inicial (década de 1970), transmitiam mensagens em prol dos direitos civis (Reynolds, 1998).

Em Portugal, hoje, a música house tem um público mais heterogéneo, de vários estratos da sociedade, mas é consumida maioritariamente por um público jovem e pelas classes média/alta (Silva, 2005). De acordo Silva, os valores que estão associados ao House, conforme os resultados do seu estudo realizado no norte de Portugal, são a sexualidade, a moda e a sensualidade. Os intervenientes revelaram, geralmente, uma preocupação com a moda e o gosto em estar num ambiente requintado. Um outro facto apontado por Silva tem que ver com a sua ampla utilização em desfiles de moda, o que enfatiza a sua ligação com uma classe social bem diferente do techno. Vemos, portanto, que na sua fase inicial o house era considerado uma música marginal e subalterna e que, mais tarde, foi apropriada pela cultura dominante, passando a ser imagem dessa mesma cultura. Ao passar para o lado do bloco do poder, ajudou, certamente, a que os direitos e a afirmação das comunidades subalternas que lhes estavam associadas pudessem ter maior expressão social. Hoje em dia, o house não é considerado um género subalterno quando falamos dos produtos da cultura de massa ou "popular". No entanto, se o transportarmos para o universo do ensino superior de música, talvez a sua proeminência não esteja tão à vista. Neste contexto, o house pode ser considerado ainda subalterno, julgando pela insistência nos padrões musicais ocidentais "eruditos", como referenciamos na introdução, e julgando também pelos resultados da avaliação do ensino não-superior artístico em Portugal. Alguns dos currículos não são atualizados desde a década 30 do século passado (Fernandes, Ferreira, Marto, Paz \& Travassos, 2007).

Relativamente ao techno, é outro género da MED que tem a sua génese em Detroit, nos EUA, possibilitado pelo desenvolvimento de sintetizadores que são, digamos, o instrumento de eleição (Boia et al., 2010). O techno surge, primeiramente, na comunidade afro-americana e, ao contrário do house, valorizava mais músicos individuais do que os próprios clubes, não tendo a mesma expressão no público homossexual. Apesar destas diferenças, os músicos de ambos os estilos interagiram desde os primórdios.

Foi direcionado para as pistas de dança visto como "reflexo de uma angústia pós-industrial, motivada por condições de existência menos favoráveis" (Boia et al., 2010, p. 51). Podemos caracterizar a música techno pela utilização de sons artificiais, recursos à repetição, gradação tonal, estrutura ambígua e som mecânico (Boia et al., 2010). Geralmente o techno é ainda mais ritmado, minimalista e maquínico e não possui uma atmosfera de felicidade como o house.

Segundo Silva (2005), o techno, em Portugal, está associado ainda às classes sociais mais desfavorecidas, como também às drogas e à violência. Esta música, à semelhança 
do house, torna-se numa experiência física poderosa onde as pessoas "dançam de olhos fechados, com movimentos mecanizados, quase agressivos, abanando a cabeça ao ritmo imparável debitado pelo DJ de serviço" (Silva, 2005, p. 65). De acordo com as entrevistas que foram realizadas no âmbito da investigação de Silva, percebeu-se que o que chama as pessoas para ir a uma festa techno é a pujança da música, ideal para dançar e libertar a raiva e frustração muitas vezes sentidas pela sua condição social. No caso do techno, vemos que a sua associação à marginalidade e à subalternidade não foi muito alterada, e por isso não esperamos que tenha relevância musical no nível superior. Mas podemos verificar que, as associações tanto ao mainstream como ao subalterno são provenientes de tensões sociais e relações culturais que não têm que ver com a música em si.

\section{CONSIDERAÇõES FINAIS}

$\mathrm{Na}$ nota introdutória expusemos a prevalência das formas musicais "eruditas" ocidentais no currículo, que podem ainda estar presentes na contemporaneidade. Corroboramos ainda que, os termos "erudito" e "popular" derivam de construções discursivas sociais que podem, ou não, estar relacionadas com aspetos formais da própria música. Como vimos no caso da MED, que se apresenta como um estilo musical autónomo e com estéticas e conceitos bem delimitados, a escassa abordagem no ensino superior de música, em Portugal, poderá prender-se com as relações de poder entre a cultura dominante e a dominada. Os contributos deste género para o (re)pensar da música propriamente dita e o seu papel na sociedade, são inegáveis, marcando uma mudança paradigmática na área.

A MED circunda-se de profundas ambiguidades conceptuais, fruto dos diversos contextos que ela abrange, mas também, sob o ponto de vista dos Estudos Culturais, pode ser considerada uma marca de resistência contra a elitização da música e contra o bloco de poder. Apresenta-se, assim, como um instrumento de discurso político e social que reivindica a legitimação e reconhecimento das suas práticas.

\section{REFERÊNCIAS BIBLIOGRÁFICAS}

Arroyo, M. (2001). Música popular em um conservatório de música. Revista da Abem, 6, 59-67.

Boia, P. d. S.; Ferro, L. \& Guerra, P. (2010). Dance Music, sons, reflexos e trânsitos: Traços de uma cena no Norte de Portugal. In J. T. Lopes; P. S. Boia; L. Ferro \& P. Guerra (Eds.), Género e Música de Dança. Experiências, percursos e "relatos" de mulheres clubbers (pp. 39-62). Lisboa: Comissão para a Cidadania e Igualdade de Género.

Borba, T. \& Lopes-Graça, F. (1958). Dicionário de Música. Porto/Lisboa: Mário Figueirinhas Editor.

Cage, J. (1961). Silence: Lectures and writings. Hanover: University Press of New England.

Chadabe, J. \& Torres Lima, G. H. (2014). The Electronic Century. Musica Hodie, 14(1), 8-32.

Farrugia, R. (2012). Beyond the dance floor: Female DJs, techonoly and electronic dance music culture. Chicago: Intellect, Ltd. 
Fernandes, D.; do Ó, J. R.; Ferreira, M. B.; Marto, A.; Paz, A. \& Travassos, A. (2007). Estudo de Avaliação do Ensino Artístico. Lisboa: Direcção Geral de Formação Vocacional do Ministério da Educação e Faculdade de Psicologia e de Ciências da Educação da Universidade de Lisboa.

Ferreira, P. P. (2008). Transe Maquínico: quando o som e movimento se encontram na música eletrónica de pista. Horizontes Antropológicos, 29, 189-215.

Fraser, A. (2012). The Spaces, Politics, and Cultural Economies of Electronic Dance Music. Geography Compass, 6(8), 500-511. doi: 10.1111/j.1749-8198.2012.00505.x

Garnett, G. E. (2001). The aesthetics of interactive computer music. Computer Music Journal, 25(1), 21-33.

Graham, S. J. (2009). Editor's introduction. Dancecult: Journal of Electronic Dance Music Culture, 1(1), iii-vi. doi: 10.12801/1947-5403.2009.01.01.00

Grout, D. J. \& Palisca, C. V. (1988). O século XX. História da Música Ocidental. Lisboa: Gradiva.

Hall, S. (2003). Notas sobre a descontrução do "popular". In L. Sovik (Ed.), Da diáspora identidades e mediações culturais. Belo Horizonte: UFMG.

Huq, R. (2007). Beyond subculture: Pop, youth and identity in a postcolonial world. Londres: Routledge.

MacCutcheon, D.; Greasley, A. E. \& Elliott, M. T. (2016). Investigating the Value of DJ Performance for Contemporary Music Education and Sensorimotor Synchronisation (SMS) Abilities. Dancecult: Journal of Electronic Dance Music Culture, 8(1), 46-72. doi: 10.12801/1947-5403.2016.08.01.03

Martin, J. (2012). Toward authentic electronic music in the curriculum: Connecting teaching to current compositional practices. International Journal of Music Education, 30(2), 120-132. doi: $10.1177 / 0255761412439924$

McCarthy-Brown, N. (2014). Decolonizing Dance Curriculum in Higher Education: once credit at a time. Journal of Dance Education, 14, 125-129. doi: 10.1080/15290824.2014.887204

McLeod, K. (2001). Genres, Subgenres, Sub-Subgenres and More: Musical and Social Differentiation Within Electronic/Dance Music Communities. Journal of Popular Music Studies, 13(1), 59-75. doi: 10.1111/j.15331598.2001.tbooo13.x

Mota, G. (2015). A educação musical em Portugal - uma história plena de contradições. DEBATES-Cadernos do Programa de Pós-Graduação em Música, 13.

Neill, B. (2002). Pleasure Beats: Rhythm and the aesthetics of current electronic music. Leonardo Music Journal, 12, 3-6. Retirado de http://www.jstor.org/stable/1513341

Nompula, Y. (2011). Valorizing the voice of the marginalised: exploring the value of African music in education. South African Journal of Education, 31(EASA), 369-380.

Reynolds, S. (1998). Energy flash: a journey trought rave music and dance culture. Berkeley CA: Group West.

Reynolds, S. (2007). Bring the Noise. Londres: Mackays of Chatham.

Rodgers, T. (2003). On the process and aesthetics on sampling in electronic music production. Organised Sound, 8(3), 313-320. doi: 10.1017/S1355771803000293

Silva, V. A. A. (2005). Techno, House e Trance. Uma incursão pelas culturas da "Dance Music". Toxicodependências, 11(3), 63-73. 
Tanaka, A. (2006). Interaction, experience and the future of music. In K. O. Hara \& B. Brown (Eds.), Consuming Music Together: Social and Collaborative Aspects of Music Consumption Technologies (pp. 267288). Netherlands: Springer.

Tullio, E. F. (2005). O idiomatismo nas composições para percussão de Luiz D'Anunciação, Ney Rosauro e Fernando lazzetta: Análise, Edição e Performance de obras selecionadas. Comunicação apresentada no XV CONGRESSO DA ANPPOM, Rio de Janeiro.

VanWeelden, K. (2012). Classical Music as Popular Music: Adolescents' Recognition of Western Art Music. National Association for Music Education, 31, 14-24. doi: 10.1177/8755123312457883

Varèse, E., \& Wen-chung, C. (1966). The Liberation of Sound. Perpectives of new music, 5(1), 11-19.

von Hornbostel, E. M. \& Sachs, C. (1961). Classification of Musical Instruments. The Galpin Society Journal, 14, 3-29. doi: $10.2307 / 842168$

Wiltsher, N. (2016). The Aesthetics of Electronic Dance Music, Part II: Dancers, DJs, Ontology and Aesthetics. Philosophy Compass, 11(8), 426-436.

\section{NOTAS BIOGRÁFICAS}

Alexandre Ferreira é doutorando em Estudos Culturais, investigador do Centro de Estudos de Comunicação e Sociedade (CECS), do Instituto de Ciências Sociais, Universidade do Minho.

E-mail: al.barbosa.ferreira@gmail.com

Morada: Rua nova de Celeirós, n 83, 4795-425 Braga, Portugal

Jean-Martin Rabot é Professor Auxiliar. Centro de Estudos de Comunicação e Sociedade (CECS), Instituto de Ciências Sociais, Universidade do Minho.

E-mail:jmrabot@ics.uminho.pt

Morada: Universidade do Minho, Campus de Gualtar, 4710-057 Braga, Portugal

* Submetido: 29-05-2017

* Aceite: 17-07-2017 